UDC 1(091)

LBC 87.3

\title{
SPECIFICS OF EXPRESSION OF THE POETIC WORD IN THE PHILOSOPHY OF H.-G. HADAMER'S AND L. WITTGENSTEIN'S LANGUAGES ${ }^{1}$
}

\author{
Ekaterina Yu. Talalaeva \\ Tambov State University named after G.R. Derzhavin, ambov, Russian Federation
}

\begin{abstract}
The article compares the linguophilosophical views of H.-G. Gadamer and L. Wittgenstein on one of the key aspects of poetic perspective. The founder of philosophical hermeneutics, Gadamer, in many ways developed and supplemented the ideas of his outstanding mentor M. Heidegger on the special ontological role of poetry as a "pure language" with the introduction of the concept of "pure poetry" into the scientific revolution. According to Gadamer, the poetic language has only its inherent tightness. This property of poetry makes it possible to preserve the semantic unity and semantic integrity of the poetic text, and also prevents the poetic word from losing its unique intrinsic value. On the other hand, the tightness of poetry excludes the possibility of voicing it, allowing only a written fixation of the poetic text. According to Gadamer's philosophical convictions, the verbal expression of poetic utterances leads to a significant distortion of the original artistic intent. Wittgenstein, in turn, standing at the origins of analytical philosophy, insists on the impossibility of expressing poetic utterances by means of ordinary language, since they do not reflect the facts and the status quo in the world, i.e. are outside factual language. In accordance with the position of the Austrian thinker, everything that does not correlate with logically correct speaking should be immersed in the sphere of silence. Nevertheless, both philosophers agreed in their arguments that the problem of the unpredictability of a poetic word can be solved with the phenomenon of showing, which can convey the meaning of a poetic work in a different way. The show does not belong to the field of language or silence, but is able to fully express the meaning of the poetic work.

Key words: poetry, pure language, language game, silence, showing, H.-G. Gadamer, L. Wittgenstein.
\end{abstract}

УДК 1(091)

ББК 87.3

\section{СПЕЦИФИКА ВЫРАЖЕНИЯ ПОЭТИЧЕСКОГО СЛОВА В ФИЛОСОФИИ ЯЗЫКА Х.-Г. ГАДАМЕРА И Л. ВИТГЕНШТЕЙНА ${ }^{1}$}

\author{
Екатерина Юрьевна Талалаева
}

Тамбовский государственный университет им. Г.Р. Державина, г. Тамбов, Российская Федерация

\begin{abstract}
Аннотация. В статье проводится сопоставление лингвофилософских воззрений Х.-Г. Гадамера и Л. Витгенштейна на один из ключевых аспектов поэтической проблематики. Основатель философской герменевтики Гадамер во многом развил и дополнил представления своего выдающегося наставника М. Хайдеггера об особой онтологической роли поэзии как «чистого языка» при помощи введения в научный оборот концепции «чистая поэзия». Согласно Гадамеру, поэтический язык обладает только ему присущей герметичностью. Данное свойство позволяет сохранять смысловое единство и семантическую целостность поэтического текста, а также препятствует утрате поэтическим словом его уникальной самоценности. Однако герметичность по$\infty$ эзии исключает возможность ее озвучивания, допуская лишь письменное фиксирование поэтического текста. 尺̄ Согласно философским убеждениям Гадамера, вербальное выражение поэтических высказываний приводит ீ. к существенному искажению оригинального художественного замысла. В свою очередь, Витгенштейн, стоя у истоков аналитической философии, настаивает на невозможности выражения поэтических высказываний \% есть находятся за границей фактуального языка. В соответствии с позицией австрийского мыслителя все, что не с собносится с логически правильным говорением, должно быть погружено в сферу молчания. Тем не менее (2) оба философа в своих рассуждениях сходились во мнении, что проблема невысказываемости поэтического
\end{abstract}


слова может быть решена при помощи феномена показывания, способного передать смысл поэтического произведения иным способом. Показывание не принадлежит области языка или молчания, но способно в полной мере выразить смысл поэтического произведения.

Ключевые слова: поэзия, чистый язык, языковая игра, молчание, показывание, Х.-Г. Гадамер, Л. Витгенштейн.

\section{Введение}

Языковая проблематика в современном мире привлекает к себе внимание различных научных дисциплин. Особую актуальность в данной связи приобретает конструктивное применение в лингвистических исследованиях наработок из области философской герменевтики и аналитической философии. Это во многом обусловлено практической эффективностью вовлечения научного философского аппарата в разработку решений проблем в сфере филологии. В частности, изучение специфики поэтического дискурса выходит за рамки филологической науки. Более того, поэзия является одним из ключевых объектов исследования в философии с позиции экзистенциальной аналитики бытия. Эта тема находится в центре рассмотрения различных философских школ, что обусловливает необходимость поиска наиболее продуктивных подходов к выявлению сущности поэзии и решению сопутствующих проблем при исследовании поэтического языка. В данной работе представлена попытка сопоставить оригинальные воззрения представителей философской герменевтики и аналитической философии в отношении такого аспекта поэтической проблематики, как невыразимость поэтического текста средствами устной речи. Наиболее плодотворным в этом плане представляется компаративный анализ принципиально разных философских установок Х.-Г. Гадамера и Л. Витгенштейна. Несмотря на существенные различия в своих методологических подходах, оба философа пришли к схожим выводам относительно эпистемических возможностей поэтического языка.

\section{I. Х.-Г. Гадамер о «герметичности» поэтического языка}

В своих философских сочинениях Гадамер развил и дополнил концепцию поэзии как «чистого языка», введенную в научный оборот его учителем М. Хайдеггером. Для не- мецкого мыслителя поэтический язык имел преимущественно сакральное значение и выступал в качестве залога способности человека осуществлять собственное бытийствование в мире. В соответствии с хайдеггеровским видением сущности поэзии поэтический язык обладает несомненно большей значимостью по сравнению с самим поэтом как выразителем поэтической речи. Именно независимость поэзии от личностных качеств поэта и его собственного жизненного опыта позволяет говорить о ней как о «чистом» языке. Переняв от своего наставника представления об особой онтологической роли поэтического языка и его принципиальном отличии от повседневной речи, Гадамер отдельно выделил специфическое состояние языка в его превосходной степени - «чистую поэзию». Для понимания сущности данного концепта необходимо предварительно рассмотреть, как немецкий философ понимал специфику языка в качестве целостного феномена.

Ключевым аспектом своего лингвофилософского анализа Гадамер представлял материальность языка, которую живая речь обретает в своей форме и звучании. Материальность языка - это своего рода «место, где могут и должны быть изложены все мысли» $[11$, p. 135]. При этом такой подход не означает, что мышление должно сводиться исключительно к артикуляции языка или фиксированию определенных высказываний. Скорее под материальностью языка следует понимать физическое воплощение его смысла, находящегося в неразрывной связи с мыслительными процессами. Этим объясняется несогласие Гадамера с Хайдеггером в том, что язык имеет многоуровневую структуру, расположенную в иерархическом порядке (от обыденной речи до хваления, которому и предшествует поэтический язык) [8, с. 247].

Тем не менее Гадамер отграничивает поэзию от повседневной речи, хотя и на несколько иных основаниях, чем это было сделано его учителем. Философ придерживался 
мнения, что обыденный язык функционирует осмысленно лишь в контексте определенной жизненной ситуации [10, p. 136]. Подобные воззрения о социально-ориентированной природе языка, с одной стороны, во многом соотносятся с представлениями Хайдеггера, характерными для раннего периода его философствования. В «Бытии и времени» немецкий философ утверждал, что проявление языка в мире носит социальный характер и обусловлено потребностью людей выстраивать совместно-разделяемый мир на основе регулируемых языком социальных норм [9, с. 118]. С другой стороны, размышления Гадамера в значительной мере согласуются с витгенштейновской концепцией «языковых игр». Однако если Витгенштейн рассматривал языковые игры сугубо в прагматическом аспекте, то для Гадамера игра - это «способ бытия» [4, c. 147]. Подобно тому, как Хайдеггер утверждал, что язык говорит (Sprache spricht) (через человека), указывая на главенствующую роль языка по отношению к человеку, Гадамер пишет: «Играющий познает игру как превосходящую его действительность» [4, c. 155]. Тем не менее понятие игры довольно сложно применить к поэтическому творчеству в силу особой онтологической значимости поэзии. Поэтому, чтобы провести четкую грань между поэтическим и обыденным языком, Гадамер обращается к средствам философской герменевтики.

Слово обыденного языка становится осмысленным благодаря его интерпретации в контексте какой-либо ситуации, но такое слово не является замкнутым или «самодостаточным»: «слово, произнесенное в связи с конкретным действием, не замкнуто на себя; оно вообще "не замкнуто", а является переходным моментом к содержанию сказанного» [6, c. 117]. Напротив, поэтическое слово является внеконтестуальным, и его значение не подвергается трансформации в зависимости от ситуации его употребления. Для того, чтобы более наглядно изложить эту идею, Гадамер привлекает к своим рассуждениям известное высказывание французского поэта и философа П. Валери о соотношении между словом повседневного и поэтического языка. В основе суждения французского мыслителя лежит существенное различие между очевидной са- моценностью золотой монеты и относительной значимостью денежной купюры или банковской банкноты, «чья ценность или же то, что мы "ценностью" именуем, требует забвения их действительной сущности» [1, с. 316]. Другими словами, обыденная речь лишь отсылает к подлинным вещам, не имея собственной значимости в отрыве от контекста употребления. Но если значение поэтического слова остается неизменным в любой ситуации, то это порождает значительную трудность при интерпретации его смыслового контента. Более того, задача усложняется после обоснования Гадамером понятия «чистая поэзия» (poésie pure). Впервые эта идея получила широкую известность благодаря деятельности поэта-символиста С. Малларме, но в философии Гадамера она приобрела новое значение. Согласно мнения немецкого мыслителя, «чистая поэзия» представлена в качестве предельной языковой формы лирическим стихотворением, которое в изначальном виде воплощает в себе «неотделимость произведения искусства от оригинальности его языкового выражения» [6, с. 120]. В отличие от незамкнутого обыденного языка, лирическая поэзия замыкается на себе, то есть пребывает в герметичном («непрозрачном» для повседневной речи) состоянии. Эта герметичность является гарантом сохранения целостности и смыслового единства поэтического текста, благодаря чему ценность слова остается неизменной. Гадамер особо подчеркивал, что «герметичность такой лирики в конце концов совершенно необходима в эпоху средств массовой коммуникации» [6, с. 121]. Однако лирическая поэзия, несмотря на ее выше обозначенные преимущества, ставит перед исследователями текста серьезную проблему.

Герметичность поэтического языка в силу своих сущностных характеристик исключает возможность выражения в устной речи. В отношении повседневного языка, зафиксированного письменным образом, и письма как такового Гадамер вполне определенно изъясняется о том, что оно, «во всей полноте своего смысла, вновь обретает язык, лишь только кто-то начинает читать» $[5$, c. 132]. Однако сам процесс чтения вслух представляется немецкому философу «одним 
из самых темных и нуждающихся в герменевтическом анализе» [5, с. 132]. Касательно поэзии Гадамер утверждает, что все, являясь «произведением художественной словесности, выступает в этом качестве как письменный текст, который опережает любое свое звуковое воплощение» [5, с. 134-135]. Для философа «произведение художественной литературы своим бытием в известной степени предназначено для “внутреннего уха”» [5, с. 134]. Таким образом, только «внутреннему уху» доступно уловить «идеальный языковой образ», который невозможно услышать в артикуляции языка посредством человеческого голоса: «Ведь идеальный языковой образ требует от человеческого голоса невозможного» [5, с. 134]. Такой подход Гадамера применим преимущественно к лирической поэзии, «которую нельзя читать вслух, поскольку говорение становится здесь говорением-внутрьсебя» [5, с. 135]. Это приводит нас к выводу, что, совершая акт творения стихотворного произведения, поэт хранит о нем молчание, так как выговоренное слово, в отличие от зафиксированного на письме, само в себе ничего не содержит.

\section{II. Л. Витгенштейн о границах фактуального языка и молчании}

Философско-герменевтическое обоснование Гадамером невыразимости поэтического языка во многом созвучно с воззрениями раннего Витгенштейна. Австрийский мыслитель утверждал, что на языке могут быть выражены только факты мира; следовательно, тексты, в которых «ни одно слово не подразумевает того, что оно значит» [6, с. 122], нужно обходить молчанием. В тезисах своего раннего труда - «Логико-философского трактата» - Витгенштейн не касается напрямую поэтической проблематики, однако его концепция молчания заслуживает пристального внимания в данном исследовании.

Первый тезис «Трактата» Витгенштейна гласит: «Мир есть все, что происходит» [2, c. 5]. Тем не менее дальнейшие рассуждения философа приводят к пониманию того, что мир составляют расположенные в логическом пространстве факты. Все, что не является фактом и не имеет своего отображения в логи- ческой структуре языка, не может быть выражено посредством последнего. Витгенштейн завершает свой фундаментальный труд тезисом «о чем невозможно говорить, о том следует молчать» [2, с. 73]. Следовательно, в сферу молчания австрийский мыслитель включает все суждения о смысле жизни, религиозной вере, этических и эстетических представлениях и иных подобных вещах. К этой же области вполне правомерно отнести иносказательные поэтические произведения. Словом, все то, что неизменно присутствует в жизни большинства людей в той или иной мере, согласно представлениям Витгенштейна, должно быть погруженным в молчание. Логично предположить, что философ наделял это понятие совершенно особым смыслом: молчание - это не просто глухое безмолвие, в котором угасла мысль. Как писал К. Лоун: «...картина полноценного живого языка остается незавершенной без риторических и метафорических высказываний. Являясь чемто большим, чем приукрашивание, они составляют жизненную основу повседневной речи и письма» [12, p. 126]. По сути, молчание представляет собой «отсутствие логически правильного говорения» [7, с. 201]. То есть все, что расположено за границей логически правильных высказываний на языке, имеющих в своей структуре непосредственное отображение фактов мира, следует хранить в молчании.

Однако это наводит на мысль, что молчание должно занимать более приоритетное положение в сравнении с обыденным (в данном случае - фактуальным) языком, так как именно оно имеет возможность сохранить и передать всю полноту смысла, заложенную в поэтическом произведении. Если вспомнить аналогию П. Валери, проведенную между монетой из драгоценного металла и поэтическим словом, то логично предположить, что такое слово должно само указывать на собственную ценность. Вновь обращаясь к размышлениям раннего Витгенштейна, мы можем подтвердить это предположение его суждением, согласно которому то, что не может быть сказано, «показывает себя» [2, с. 73]. Феномен показывания играет одну из ключевых ролей в «Трактате» философа. С одной стороны, он не относится к логическим фак- 
там мира, тогда как с другой - не побуждает к молчанию. «Показывание не принадлежит молчанию, но вместе с тем оно не есть акт осмысленного говорения» [7, с. 203]. Тем не менее именно показывание, которое не относится к говорению или молчанию, способно донести до остальных людей идею, заключенную поэтом в сложенное им стихотворение. Таким образом, показывание не просто один из возможных способов изложения мысли, но, пожалуй, единственный способ выразить смысл поэтического произведения.

\section{Заключение}

Анализ исследуемой проблемы показал, что, несмотря на явные различия в методологических установках двух ведущих западноевропейских философских традиций, их ключевые представители приходят к схожим выводам относительно возможности выражения на языке поэтического слова. Философские воззрения Гадамера и Витгенштейна на природу языка имеют существенные различия, однако оба философа согласились бы, что поэзия не предназначена для ее озвучивания вслух.

Согласно герменевтической философии Гадамера, поэтический язык обладает только ему присущей герметичностью, что защищает поэтический текст от вольной трактовки составляющих его частей вне единого контекста всего произведения. В этом свете поэзия приобретает статус качественно иного состояния языка в сравнении с повседневной речью. Если Гадамер избрал исключительно контекстуальный подход в отношении обыденного «разговорного, чисто коммуникативного слова», которое «только значит нечто, но внутри себя оно - ничто» [5, с. 136], то поэтическое слово в представлении философа является самоценным по своей сути. Особое качественное состояние поэтического языка предполагает, прежде всего, наличие у него оригинальной формы и созвучности с жизнью, что защищает поэтическое слово от обесценивания и утраты своей истинности с течением времени.

В теории Витгенштейна чистое поэтическое слово, изложенное в художественном произведении, неизменно пребывает во временном настоящем, в отличие от слова повсед- невного языка, постепенно утрачивающего свою изначальную значимость. Именно поэтому озвучивание поэзии не только сторонним читателем, но и непосредственно самим автором приводит к значительному искажению оригинального смысла текста. Аналитический подход Витгенштейна доказывает также, что если поэтический текст не является моделью какой-либо ситуации и не отражает в своей структуре определенных фактов мира, то он в принципе не может быть выражен средствами языка: нам остается только молчать о нем. Тем не менее Гадамер и Витгенштейн сходятся во мнении, что слово поэтического языка, обладая присущей ему самоценностью, наделено способностью показывать заложенный в него смысл.

\section{ПРИМЕЧАНИЕ}

${ }^{1}$ Исследование выполнено при финансовой поддержке РФФИ в рамках научного проекта № 17-33-01099-ОГН «Онтологический анализ поэзии в герменевтической философии мыслителей ХХ в.».

\section{СПИСОК ЛИТЕРАТУРЫ}

1. Валери, П. Вопросы поэзии // Об искусстве / П. Валери. - М. : Искусство, 1993.-С. 299-313.

2. Витгенштейн, Л. Логико-философский трактат // Философские работы. В 2 ч. Ч. 1 / Л. Витгенштейн ; пер. с нем. М. С. Козловой, Ю. А. Асеева. М. : Гнозис, 1994. - С. 1-74.

3. Витгенштейн, Л. Философские исследования // Философские работы. В 2 ч. Ч. 1 / Л. Витгенштейн ; пер. с нем. М. С. Козловой, Ю. А. Асеева. М. : Гнозис, 1994. - С. 75-320.

4. Гадамер, Х.-Г. Истина и метод: Основы филос. герменевтики : пер. с нем. / Х.-Г. Гадамер ; общ. ред. и вступ. ст. Б. Н. Бессонова. - М. : Прогресс, 1988. $-704 \mathrm{c}$.

5. Гадамер, Х.-Г. Философия и литература // Актуальность прекрасного / Х.-Г. Гадамер ; пер. с нем. - М. : Искусство, 1991. - С. 126-146.

6. Гадамер, Х.-Г. Философия и поэзия // Актуальность прекрасного / Х.-Г. Гадамер ; пер. с нем. - М. : Искусство, 1991. - С. 116-125.

7. Медведев, Н. В. Роль молчания в онтологии языка Витгенштейна и Хайдеггера / Н. В. Медведев, Е. Ю. Федотова // Каспийский регион: политика, экономика, культура. - 2015. - № 1 (42). C. 199-209. 
8. Чернова, Я. С. Трагедия как исток поэтической речи в философии М. Хайдеггера и П. Рикера / Я. С. Чернова, Е. Ю. Талалаева // Исторические, философские, политические и юридические науки, культурология и искусствоведение. Вопросы теории и практики. - Тамбов : Грамота, 2017. № 12 (86), ч. 5. - С. 246-249.

9. Хайдеггер, М. Время и Бытие: Статьи и выступления : пер. с нем. - М. : Республика, 1993. 447 с. - (Мыслители XX в.).

10. Gadamer, H.-G. The Relevance of the Beautiful and Other Essays / H.-G. Gadamer. - Cambridge : Cambridge University Press, 1986. - 191 p.

11. Grondin, J. The Philosophy of Gadamer / J. Grondin, K. Plant. - L. : Routledge, 2014. - 192 p.

12. Lawn, C. Wittgenstein and Gadamer: towards a post-analytic philosophy of language / C. Lawn. L. : A\&C Black, 2004.-161 p. - (Continuum Studies in Germany Philosophy).

\section{REFERENCES}

1. Valeri P. Voprosy poezii [The Questions about Poetry]. Valeri P. Ob iskusstve [About Art]. Moscow, Iskusstvo Publ., 1993, pp. 299-313.

2. Vitgenshteyn L. Logiko-filosofskiy traktat [Tractatus Logico-Philosophicus]. Vitgenshteyn L. Filosofskie raboty. V2 ch. Ch. 1 [Philosophical Works. In 2 Parts. Part 1]. Moscow, Gnozis Publ., 1994, pp. 1-74.

3. Vitgenshteyn L. Filosofskie issledovaniya [Philosophical Investigations]. Vitgenshteyn L. Filosofskie raboty. V2 ch. Ch. 1 [Philosophical Works. In 2 Parts. Part 1]. Moscow, Gnozis Publ., 1994, pp. 75-320.
4. Gadamer H.-G. Istina i metod: Osnovy filos. germenevtiki [Truth and Method: Basis of Philosophical Hermeneutics]. Moscow, Progress Publ., $1988.704 \mathrm{p}$.

5. Gadamer H.-G. Filosofiya i literatura [Philosophy and Literature]. Gadamer H.-G. Aktualnost prekrasnogo [The Relevance of the Beautiful]. Moscow, Iskusstvo Publ., 1991, pp. 126-146.

6. Gadamer H.-G. Filosofiya i poeziya [Philosophy and Poetry]. Gadamer H.-G. Aktualnost prekrasnogo [The Relevance of the Beautiful]. Moscow, Iskusstvo Publ., 1991, pp. 116-125.

7. Medvedev N.V., Fedotova E.Yu. Rol molchaniya v ontologii yazyka Vitgenshteyna i Khaydeggera [The Role of Silence in the Wittgenstein's and Heidegger's Ontology of Language]. Kaspiyskiy region: politika, ekonomika, kultura, 2015, no. 1 (42), pp. 199-209.

8. Chernova Ya.S., Talalaeva E.Yu. Tragediya kak istok poeticheskoy rechi $v$ filosofii $M$. Khaydeggera $\mathrm{i}$ P. Rikera [The Tragedy as the Origin of Poetry in the Philosophy of M. Heidegger and P. Ricær]. Gramota, 2017, no. 12 (86), part 5, pp. 246-249.

9. Heidegger M. Vremya $i$ Bytie: Statyi $i$ vystupleniya [Time and Being: articles and speeches: Trans. from German]. Moscow, Respublika Publ., 1993. 447 p.

10. Gadamer H.-G. The Relevance of the Beautiful and Other Essays. Cambridge, Cambridge University Press, 1986. $191 \mathrm{p}$.

11. Grondin J., Plant K. The Philosophy of Gadamer. London, Routledge, 2014. 192 p.

12. Lawn C. Wittgenstein and Gadamer: Towards a post-analytic philosophy of language (Continuum Studies in Germany Philosophy). London, A\&C Black, 2004. 161 p.

\section{Information about the Author}

Ekaterina Yu. Talalaeva, graduate student of the Department of Philosophy and Methodology of Science, Tambov State University named after G.R. Derzhavin Internatsionalnaya St., 33, 392000 Tambov, Russian Federation, kater-.-ina@mail.ru.

\section{Информация об авторе}

Екатерина Юрьевна Талалаева, аспирант кафедры философии и методологии науки, Тамбовский государственный университет им. Г.Р. Державина, ул. Интернациональная, 33, 392000 г. Тамбов, Российская Федерация, kater-.-ina@mail.ru. 